\title{
Recent Progress in the development of Neodymium doped Ceramic Yttria
}

\author{
Narasimha S. Prasad ${ }^{\mathrm{a}}$, Chris Edwards ${ }^{\mathrm{a}}$, Sudhir B. Trivedi ${ }^{\mathrm{b}}$, Susan Kutcher ${ }^{\mathrm{b}}$, Chen-Chia Wang ${ }^{\mathrm{b}}$, \\ Joo-Soo Kim ${ }^{\mathrm{b}}$, Uwe Hommerich ${ }^{\mathrm{c}}$, Vijay Shukla ${ }^{\mathrm{d}}$, Rajendra Sadangi ${ }^{\mathrm{d}}$, and Bernard Kear ${ }^{\mathrm{d}}$ \\ ${ }^{a}$ NASA Langley Research Center, 5 N. Dryden St., MS 468, Hampton, VA 23681-2199 \\ ${ }^{b}$ Brimrose Corporation, 19 Loveton Cir., Baltimore, MD 21152 \\ ${ }^{\mathrm{c}}$ Hampton University, Department of Physics, Hampton, VA 23668 \\ ${ }^{\mathrm{d}}$ State University of New Jersey, Rutgers, Center for Nanomaterials Research, School of \\ Engineering, Busch Campus, 98 Brett Rd., Piscataway, NJ 08854-8058
}

\begin{abstract}
Solid-state lasers play a significant role in providing the technology necessary for active remote sensing of the atmosphere. Neodymium doped yttria $\left(\mathrm{Nd}: \mathrm{Y}_{2} \mathrm{O}_{3}\right)$ is considered to be an attractive material due to its possible lasing wavelengths of $\sim 914 \mathrm{~nm}$ and $\sim 946 \mathrm{~nm}$ for ozone profiling. These wavelengths when frequency tripled can generate UV light at $\sim 305 \mathrm{~nm}$ and $\sim 315 \mathrm{~nm}$, which is particularly useful for ozone sensing using differential absorption lidar technique. For practical realization of space based UV transmitter technology, ceramic $\mathrm{Nd}: \mathrm{Y}_{2} \mathrm{O}_{3}$ material is considered to possess great potential. A plasma melting and quenching method has been developed to produce $\mathrm{Nd}^{3+}$ doped powders for consolidation into $\mathrm{Nd}: \mathrm{Y}_{2} \mathrm{O}_{3}$ ceramic laser materials. This far-from-equilibrium processing methodology allows higher levels of rare earth doping than can be achieved by equilibrium methods. The method comprises of two main steps: (a) plasma melting and quenching to generate dense, and homogeneous doped metastable powders, (b) pressure assisted consolidation of these powders by hot isostatic pressing to make dense nanocomposite ceramics. Using this process, several 1" 1 1" ceramic cylinders have been produced. The infrared transmission of undoped $\mathrm{Y}_{2} \mathrm{O}_{3}$ ceramics was as high as $\sim 75 \%$ without anti-reflection coating. In the case of $\mathrm{Nd}: \mathrm{Y}_{2} \mathrm{O}_{3}$ ceramics infrared transmission values of $\sim 50 \%$ were achieved. Furthermore, $\mathrm{Nd}: \mathrm{Y}_{2} \mathrm{O}_{3}$ samples with dopant concentrations of up to $\sim 2$ at. $\%$ were prepared without significant emission quenching.
\end{abstract}

Index Terms- Remote Sensing, solid-state lasers, ceramics, Neodymium doped yttria 


\section{INTRODUCTION}

NASA is actively engaged in the development of space-based active remote sensing missions using Light Detection And Ranging (LIDAR) techniques. Under the ongoing Laser Risk Reduction Program (LRRP), the emphasis is on the development of reliable and robust lasers for LIDAR systems appropriate for space based platforms. One of the technical objectives of LRRP is to develop viable one micron laser based all-solid-state UV transmitter technologies generating dual wavelengths around $308 \mathrm{~nm}$ and $320 \mathrm{~nm}$ for ozone profiling using Differential Absorption Lidar (DIAL) scheme. Basic design considerations involved several practical orbital and environmental operational conditions. Accordingly, for operation during strong day light conditions, a highly efficient, single longitudinal mode, conductively cooled, and all-solid-state UV transmitter scheme has been developed. The scheme involves a Nd:YAG pump laser operating at $1064 \mathrm{~nm}$ that is coupled to a nonlinear optics arrangement comprising of an optical parametric oscillator (OPO) and a sum frequency generator (SFG) that generates $>200 \mathrm{~mJ} /$ pulse [1]. In this case, the overall transmitter scheme is relatively complex.

To simplify the UV transmitter architecture, several approaches are being contemplated. One of the approaches that NASA is actively engaged in is the development of novel laser materials that could conveniently provide UV wavelengths. Solid state tunable lasers based on single crystalline medium have significantly contributed towards the development of technology necessary for active remote sensing of the atmosphere from terrestrial, airborne and space based platforms. However, many recent studies on diode-pumped solid-state lasers have focused on polycrystalline ceramic lasers because of the advantages that they have over single crystals in terms of shape, size, ease of fabrication, and control of dopant concentrations [2-10].

Significant strides have been made in the development of ceramic neodymium doped Yttrium Aluminum Garnet (Nd:YAG) material [2-5]. Neodymium doped $\mathrm{Yttria}\left(\mathrm{Nd}: \mathrm{Y}_{2} \mathrm{O}_{3}\right)$ is another material that has attracted considerable attention due to its lasing wavelengths and excellent thermo-mechanical properties [6-11]. The specific Stark level splittings in $\mathrm{Nd}: \mathrm{Y}_{2} \mathrm{O}_{3}$ provides two emission lines at $914 \mathrm{~nm}$ and $946 \mathrm{~nm}$ originating from the ${ }^{4} \mathrm{~F}_{3 / 2} \rightarrow{ }^{4} \mathrm{I}_{9 / 2}$ transition. Unlike $\mathrm{Nd}: \mathrm{YAG}$, the $\mathrm{Nd}: \mathrm{Y}_{2} \mathrm{O}_{3}$ gain medium, besides $1064 \mathrm{~nm}$ wavelength, is capable of generating 914 $\mathrm{nm}$ and $946 \mathrm{~nm}$ wavelengths which when tripled will provide wavelengths around $305 \mathrm{~nm}$ and $315 \mathrm{~nm}$. These two wavelengths are particularly useful in ozone sensing using the DIAL technique. Nd: $\mathrm{Y}_{2} \mathrm{O}_{3}$ not only possesses the requisite peak wavelengths at 914 and $946 \mathrm{~nm}$ for

${ }^{4} \mathrm{~F}_{3 / 2} \rightarrow{ }^{4} \mathrm{I}_{9 / 2}$ emission but also has a relatively large Stark splitting of the ground state that is somewhere between garnets and fluorides. It has emission cross-sections approaching those in $\mathrm{Nd}: \mathrm{YAG}$, and it has the smallest $1.06 \mu \mathrm{m} / 0.94 \mu \mathrm{m}$ cross-section ratio of any $\mathrm{Nd}$ doped material commonly known. All of these characteristics make $\mathrm{Nd}: \mathrm{Y}_{2} \mathrm{O}_{3}$ an excellent candidate for study toward applications for atmospheric ozone DIAL measurements [11].

The cubic $\mathrm{Y}_{2} \mathrm{O}_{3}$ single crystal has several favorable properties such as a refractory nature, stability, and optical clarity over a broad spectral range [5-11]. Furthermore, the thermal conductivity and thermal expansion coefficients are very similar to those of YAG. According to certain conservative estimates, the thermal conductivity of $\mathrm{Nd}: \mathrm{Y}_{2} \mathrm{O}_{3}$ is nearly twice that of $\mathrm{Nd}$ :YAG. However, the yttria single crystal has a high melting temperature $\left(2430^{\circ} \mathrm{C}\right)$ and a structural phase transition at $2280^{\circ} \mathrm{C}$. Thus, it is extremely difficult to grow large-sized high quality yttria single crystals. It is, however, relatively easy to fabricate yttria ceramics because the sintering temperature is about $700^{\circ} \mathrm{C}$ lower than the melting temperature. 
In recent years, Japanese researchers [2-10] have used polycrystalline ceramics as a new type of laser gain media. Ceramic materials can be processed/produced at temperatures that are about two-thirds their melting points. They can be produced in large sizes, a variety of shapes, and best of all, with dopant concentrations about an order of magnitude higher than those in single crystal materials. In case of a dopant like $\mathrm{Yb}^{3+}$ where emission concentration quenching effects are practically absent, it is possible to produce ceramic laser materials with higher concentration to generate efficient lasing. Finally, with the short fabrication time and its amenability to large scale production, the cost of ceramic laser materials could be much lower than traditional laser materials.

Production of ceramic laser materials in the USA is in its initial stages. Most of the optical ceramic activity had been focused at producing transparent window material with superior thermo-mechanical properties for applications at infrared wavelengths [12]. In recent years, we have made significant progress in producing ceramic laser materials. We have overcome two major challenges in this area: 1) production of transparent ceramic material and 2) achievement of homogeneous rare earth doping. We have successfully produced $\mathrm{Nd}: \mathrm{Y}_{2} \mathrm{O}_{3}$ with emission characteristics as good as single crystalline material. The uniqueness of our approach is in producing rare earth doped ceramic powders using a plasma spray process, followed by consolidation in green body form and subsequent hot isostatic pressing (HIP) of these powders. Rare earth doping in this process is carried out in the far-from-equilibrium regime that results in powder in a metastable state. This powder can have doping levels much higher than via the sintering/diffusion process. Also, as the powder has experienced a high temperature during formation, it can be consolidated while retaining these higher doping levels.

In this paper, we report on the recent progress made in the development of $\mathrm{Nd}: \mathrm{Y}_{2} \mathrm{O}_{3}$ ceramics as a solid-state laser material primarily for remote sensing applications of atmospheric ozone [13]. In Section 2, the development of ceramic $\mathrm{Nd}: \mathrm{Y}_{2} \mathrm{O}_{3}$ by an unique processing methodology is presented. The production and characterization of metastable $\mathrm{Nd}: \mathrm{Y}_{2} \mathrm{O}_{3}$ powder and transparent ceramic disks are discussed in Section 3. Further experimental results on the absorption and emission properties of undoped and $\mathrm{Nd}$ doped $\mathrm{Y}_{2} \mathrm{O}_{3}$ powders and ceramics are discussed in Section 4.

\section{NEODYMIUM DOPED CERAMIC YTTRIA}

We have developed a far-from-equilibrium or metastable processing method to enable production of multiphase nanocomposite ceramics $[14,15]$. The new process integrates two enabling technologies: (1) Far-from-equilibrium processing to produce homogeneous metastable powders, and (2) Hot Isostatic Pressing (HIP) to densify these metastable powders, while decomposing them into nanocrystalline or nanocomposite structures. Co-nucleation of nanophases during the consolidation also limits their growth, thus creating a uniform nanocomposite structure. This method overcomes the difficulties inherent in the processing of high surface area nanocrystalline powders where unrestricted grain growth is a serious problem. Moreover, fine grain multi-phase ceramics may show superplastic flow, which improves densification.

In previous work [16-20], we investigated the feasibility of using $\mathrm{Nd}: \mathrm{Y}_{2} \mathrm{O}_{3}$ composites to produce polycrystalline nano-grain ceramic laser material. The overall goal of our collaborative effort is to develop appreciable size ceramic $\mathrm{Nd}: \mathrm{Y}_{2} \mathrm{O}_{3}$ laser materials with high $\mathrm{Nd}$ concentration quenching limits along with excellent optical quality. We have produced spherical non agglomerated and monodisperse metastable ceramic powders of undoped $\mathrm{Y}_{2} \mathrm{O}_{3}$ and $\mathrm{Nd}: \mathrm{Y}_{2} \mathrm{O}_{3}$ with 1 at. $\%$ and 2 at. $\% \mathrm{Nd}^{3+}$ ions. These powders were consolidated first to form cylinder/disk 
shape green bodies by a hydraulic press and then further densified using hot isostatic processing to produce the ceramic yttria samples. We have found in our previous work that many times the resulting material was translucent. Usually the translucent nature was a consequence of porosity in the samples. These pores act as scattering centers in the sample and prevent reasonable transmission. Through improved processing techniques we were able to produce both undoped $\mathrm{Y}_{2} \mathrm{O}_{3}$ and $\mathrm{Nd}: \mathrm{Y}_{2} \mathrm{O}_{3}$ ceramics that were transparent. We briefly describe the production method in the following Section.

\section{Nd: $\mathrm{Y}_{2} \mathrm{O}_{3}$ SAMPLE PREPARATION}

Previously, we utilized ceramic $\mathrm{Nd}: \mathrm{Y}_{2} \mathrm{O}_{3}$ samples using $\mathrm{Y}_{2} \mathrm{O}_{3}+\mathrm{Nd}_{2} \mathrm{O}_{3}$ powders of required stoichiometry $[16,17]$. To obtain highly transparent materials in a more efficient way, various modifications to this process were carried out [18-20]. This procedure yielded highly transparent ceramic samples and is described as follows.

\section{$\underline{\text { Powder production }}$}

Using the Rutgers plasma process [16], we can dope the rare earth materials, i.e. neodymium at desired levels. This is because of the high temperatures involved. The experiments described here are conducted using a Sulzer-Metco $9 \mathrm{MB}, 80 \mathrm{~kW}$ plasma system and quenching in water.

To further improve the powder quality, we have produced powder by injection of liquid chemical precursors (Yttrium nitrate and Neodymium nitrate dissolved in water) into a plasma. This new process uses a reaction tube, shown in Fig. 1. The reaction tube attachment makes provisions for rapid cooling, via expansion through a supersonic nozzle. The residence time and cooling in the plasma can be controlled by injecting extra cooling gas and by inserting an aerodynamic de-Laval nozzle in the reaction tube, which caused nanoparticles to nucleate from the vaporized gas stream. In preliminary trials, yields better than $95 \%$ have been obtained. Consolidation experiments on these powders will be described in a later work.

The microstructure and porosity of the samples were evaluated by optical microscopy. The phase composition of the powders and dense samples were analyzed by X-ray diffraction (Fig. 2). The analysis was carried out in a Siemens D5000 diffractometer, using $\mathrm{Cu}_{\mathrm{K \alpha}}$ radiation (40 $\mathrm{kV}, 30 \mathrm{~mA}$ ), and JADE (version 7.0) for phase identification.

\section{$\underline{\text { Powder consolidation }}$}

The consolidation process chosen for this work is HIP. The powders generated by the above process can be densified into parts with microstructures that can be controlled by varying the HIP conditions. The HIP schedule can be adjusted, as shown in Fig. 3, to control the exposure of the metastable powder to maximum temperature and the time required at maximum temperature to achieve full densification. As a result, the structure and porosity of the densified part can be controlled. During consolidation a steel HIP canister with a diameter of $25.4 \mathrm{~mm}$ (1") and length of $25.4 \mathrm{~mm}$ (1") was used. The canister was coated with Boron Nitride and filled with the powders produced. This container was then evacuated, at $300{ }^{\circ} \mathrm{C}$, and e-beam welded. Typical HIP schedules used for experiments are illustrated in Fig. 3 where pressure and temperature measurements taken during the HIP run are shown.

A low temperature hold enables thermal equilibrium in the material and a subsequent high temperature hold ensures a fully dense material. The low temperature hold and high temperature 
hold can be seen in Fig. 3. Several experiments have been performed to identify the temperature window in which consolidation occurs. However, the starting materials need to be of high purity. For HIP to be effective, uniform starting powder sizes, high starting purities, and a wide processing window is necessary. In the case of undoped $\mathrm{Y}_{2} \mathrm{O}_{3}$ we have achieved transparency higher than in the case of doped material. This was primarily due to the fact that the size of the dopant powder used was not same as the $\mathrm{Y}_{2} \mathrm{O}_{3}$ powder, the densification was affected adversely by the powder size difference.

\section{OPTICAL CHARACTERIZATION}

The optical properties of undoped and $\mathrm{Nd}$ doped $\mathrm{Y}_{2} \mathrm{O}_{3}$ powders and ceramic disks were determined through transmission, absorption, and emission spectroscopy. The preliminary ceramic samples were translucent in nature due to compaction/HIP problems. For efficient lasing, the ceramic material needs to be transparent at IR emission wavelengths with good optical quality. In our case optical quality implies achieving uniform dopant distribution and single phase characteristics, minimal porosity and grain size compatible with emission wavelengths for minimal scattering.

\section{Powders:}

Prior to preparing the transparent ceramic disks, we performed emission studies on powder samples using $800 \mathrm{~nm}$ diode laser excitation. As expected, undoped $\mathrm{Y}_{2} \mathrm{O}_{3}$ powders did not exhibit any near-IR emission. 1 at. $\%$ and 2 at. $\% \mathrm{Nd}: \mathrm{Y}_{2} \mathrm{O}_{3}$ powders samples showed intense $\mathrm{Nd}^{3+}$

emission lines in the $\sim 900-1000 \mathrm{~nm}$ range $\left({ }^{4} \mathrm{~F}_{3 / 2^{-}}>^{4} \mathrm{I}_{9 / 2}\right), \sim 1050-1150 \mathrm{~nm}\left({ }^{4} \mathrm{~F}_{3 / 2^{-}}>^{4} \mathrm{I}_{11 / 2}\right)$, and $\sim 1300-1450 \mathrm{~nm}\left({ }^{4} \mathrm{~F}_{3 / 2}->^{4} \mathrm{I}_{13 / 2}\right)$ (see Fig. 4) [6,11]. The linewidth of the emission features was limited by the resolution of the emission setup. As discussed earlier, the lines at $914 \mathrm{~nm}$ and 946 $\mathrm{nm}$ are of interest for UV ozone lidar applications. The emission lifetime of the $946 \mathrm{~nm}$ line was determined to be $\sim 140 \mu$ s and $\sim 80 \mu$ s for the 1 at $\%$ and 2 at $\% \mathrm{Nd}: \mathrm{Y}_{2} \mathrm{O}_{3}$ powder, respectively. The decrease in lifetime with higher $\mathrm{Nd}$ concentration is possibly due to concentration quenching. Some improvement of emission lifetime was achieved through annealing studies. For, example annealing the 2 at $\% \mathrm{Nd}: \mathrm{Y}_{2} \mathrm{O}_{3}$ powder at $1200^{\circ} \mathrm{C}$ increased the lifetime to $\sim 190 \mu \mathrm{s}$. Overall, the obtained $\mathrm{Nd}: \mathrm{Y}_{2} \mathrm{O}_{3}$ powders exhibited shorter emission lifetimes then that 'reported for $\mathrm{Nd}: \mathrm{Y}_{2} \mathrm{O}_{3}$ bulk crystals $(\sim 300 \mu \mathrm{s})[11]$.

\section{Ceramics:}

Ceramic boules of undoped $\mathrm{Y}_{2} \mathrm{O}_{3}$ and $\mathrm{Nd}: \mathrm{Y}_{2} \mathrm{O}_{3}$ (2 at.\%) with dimensions of up to 1"diameter x 1" length were developed. From these boules, 0.9" x 1"x $2 \mathrm{~mm}$ slices were cut and polished. Figure 5a shows a photograph of a transparent undoped $\mathrm{Y}_{2} \mathrm{O}_{3}$ sample. An example of a transparent $\mathrm{Nd}: \mathrm{Y}_{2} \mathrm{O}_{3}$ sample used in our measurements is shown in Fig. 5b. This figure also shows a translucent sample in the upper left corner for comparison.

The transmission curves of two ceramic samples over a range from 250-2000 nm are shown in Fig. 6. The undoped $\mathrm{Y}_{2} \mathrm{O}_{3}$ ceramic exhibited bandedge absorption at $\sim 250 \mathrm{~nm}$ and an IR transmission as high as $\sim 75 \%$. Note that the test samples were uncoated and hence the Fresnel losses are not accounted for. For $\mathrm{Y}_{2} \mathrm{O}_{3}$, the refractive index, n, is equal to 1.74 at $2000 \mathrm{~nm}$, which leads to $\sim 14 \%$ Fresnel reflection losses.

The Nd: $\mathrm{Y}_{2} \mathrm{O}_{3}$ ceramic sample showed a slightly reduced transmission with values of $\sim 55 \%$ at IR wavelengths. In addition, this sample also revealed characteristic $\mathrm{Nd}^{3+}$ absorption lines in the 
visible and near-IR spectral range. A high resolution absorption spectrum of the ceramic $\mathrm{Nd}: \mathrm{Y}_{2} \mathrm{O}_{3}$ sample for the range from $\sim 700-900 \mathrm{~nm}$ is shown in Fig. 7. The observed absorption features of $\mathrm{Nd}^{3+}$ ions are nearly identical to those reported for a single crystal of $\mathrm{Nd}_{2} \mathrm{Y}_{2} \mathrm{O}_{3}$ [11]. The peak absorption coefficient at $\sim 821 \mathrm{~nm}$ was determined to be $\sim 6 \mathrm{~cm}^{-1}$ with a linewidth of $\sim 1$ nm.

We then measured the emission spectra and lifetimes of un-annealed $\mathrm{Nd}: \mathrm{Y}_{2} \mathrm{O}_{3}$ consolidated ceramic samples with 2 at. $\% \mathrm{Nd}$ doping $\mathrm{HIPed}$ at $1400^{\circ} \mathrm{C}$ (see Fig. 8a). No significant spectral differences were observed for the emission from $\mathrm{Nd}: \mathrm{Y}_{2} \mathrm{O}_{3}$ powders and ceramics. It is interesting to note, that the lifetime of the $\mathrm{Nd}: \mathrm{Y}_{2} \mathrm{O}_{3}$ ceramic was more than twice as long as the powder sample [20] (see Fig. 8b). It appears that the ceramic formation process leads to a reduction of unwanted non-radiative decay losses. In an effort to further improve on the emission lifetime of $\mathrm{Nd}: \mathrm{Y}_{2} \mathrm{O}_{3}$ ceramics, annealing experiments were carried out. The lifetime increased from $\sim 230 \mu$ s before annealing to $\sim 310 \mu \mathrm{s}$ after annealing the sample at $1200^{\circ} \mathrm{C}$ for $36 \mathrm{Hr}$, which is very similar to the reported lifetime of $\mathrm{Nd}_{2} \mathrm{Y}_{2} \mathrm{O}_{3}$ single crystals [11]. Up to 2 at. $\% \mathrm{Nd}: \mathrm{Y}_{2} \mathrm{O}_{3}$ samples were prepared and no significant emission concentration quenching was observed. It appears, that higher $\mathrm{Nd}$ concentrations are possible, which would be important for applications in thin-disk lasers. Thus, in our work with ceramic $\mathrm{Nd}: \mathrm{Y}_{2} \mathrm{O}_{3}$, we successfully achieved emission and lifetime characteristics that were comparable to those found in single crystal samples.

\section{CONCLUSIONS}

In summary, advances made in material processing techniques, have successfully led to the development of highly transparent ceramic materials. We have optimized the emission and lifetime characteristics of $\mathrm{Nd}: \mathrm{Y}_{2} \mathrm{O}_{3}$ ceramics, comparable to single crystal $\mathrm{Y}_{2} \mathrm{O}_{3}$. Based on these results we have clearly established the feasibility of producing $\mathrm{Nd}: \mathrm{Y}_{2} \mathrm{O}_{3}$ as a potential ceramic laser material. Ceramic $\mathrm{Y}_{2} \mathrm{O}_{3}$ with band-edge absorption of less then $\sim 250 \mathrm{~nm}$ and uncoated sample transmission of $\sim 75 \%$ were developed. A transmission of greater than $50 \%$ for IR wavelengths was achieved for $\mathrm{Nd}: \mathrm{Y}_{2} \mathrm{O}_{3}$ ceramics. The ongoing experiments involve further improving powder preparation to address segregation issues and to improve the transmission of $\mathrm{Nd}: \mathrm{Y}_{2} \mathrm{O}_{3}$ ceramics. Also, up to 2" diameter boules are currently being prepared. Ceramic $\mathrm{Nd}: \mathrm{Y}_{2} \mathrm{O}_{3}$ has enormous potential as a solid-state laser material for ozone and other trace gas detection and bio-chemical sensing applications.

\section{ACKNOWLEDGMENTS}

This work was supported partially by NASA Phase II SBIR contract NNL04AB41P and internal R\&D funding at Brimrose Corporation. The work at Hampton University was partially supported by the National Science Foundation through grants HRD-0400041 and HRD-0630372. The work at Rutgers University has been supported by a grant from the office of naval research through grant N-00014-01-1-0079. 


\section{REFERENCES}

1. Narasimha S. Prasad, Upendra N. Singh, Floyd Hovis, Darrell J. Armstrong, "High energy single-mode all-solid-state, tunable UV laser transmitter," Proc. of SPIE, vol. 6214, 62140T, Laser Radar Technology and Applications XI; Gary W. Kamerman, Monte D. Turner; Eds. May 2006.

2. A. Ikesue, T. Kinoshita, K. Kamata and K. Yoshida, "Fabrication and optical properties of high performance polycrystalline Nd:YAG ceramics for solid-state lasers" J. Am. Ceram. Soc. vol. 78, pp.1033-1040, 1995.

3. A. Ikesue, Y. L. Aung, T. Taira, T. Kamimura, K. Yoshida, G. L. Messing, "Progress in Ceramic Lasers", Annu. Rev. Mater. Res. vol. 36, pp. 397-429, 2006.

4. J. Lu, J. Song, M. Prabhu, J. Xu, K. Ueda, H. Yagi, T. Yanagitani, A. Kudryashov, "Highpower Nd: $\mathrm{Y}_{3} \mathrm{Al}_{5} \mathrm{O}_{12}$ ceramic laser", Jpn. J. Appl. Phys. vol. 39, pp. L1048-1050, 2000.

5. J. Lu, K. Ueda, H. Yagi, T. Yanagitani, Y. Akiyama, A. Kaminskii, "Neodymium doped yttrium aluminum garnet $\left(\mathrm{Y}_{3} \mathrm{Al}_{5} \mathrm{O}_{12}\right)$ nanocrystalline ceramics: a new generation of solidstate laser and optical materials", J. Alloys Compounds, vol. 341, 220-225, 2002.

6. J. Lu, J. Lu, T. Murai, K. Takaichi, T. Uematsu, K. Ueda, H. Yagi, T. Yanagitani, A.A. Kaminskii, "Nd ${ }^{3+}: \mathrm{Y}_{2} \mathrm{O}_{3}$ ceramic laser", Jpn. J. Appl. Phys., vol. 40, pp. L1277-L1279, 2001.

7. J. Kong, J.Lu, K. Takaichi,, T. Uematsu, K. Ueda, D.Y. Yang, D.Y. Shen, H. Yagi, T. Yanagitani, and A.A. Kaminskii. "Diode pumped $\mathrm{Yb}: \mathrm{Y}_{2} \mathrm{O}_{3}$ ceramic laser," Appl. Phys. Lett., vol. 82, pp. 2556-2558, 2003.

8. J. Lu, K. Takaichi, T. Uematsu, A. Shirakawa, M. Musha, K. Ueda, H. Yagi, T. Yanagitani and A. A. Kaminskii, "Promising Ceramic Laser Material: Highly Transparent $\mathrm{Nd}^{3+}: \mathrm{Lu}_{2} \mathrm{O}_{3}$ Ceramic," Appl. Phys. Lett., vol. 81, pp. 4324, 2002.

9. Shirakawa, K. Takaichi, H. Yagi, J-F. Bisson, J. Lu, M. Musha, and K. Ueda, "Diodepumped Mode-locked $\mathrm{Yb}^{3+}: \mathrm{Y}_{2} \mathrm{O}_{3}$ Ceramic Laser," Optics Express, vol. 11, pp. 2911-2916, 2003.

10. J. Kong and D. Y. Tang, J. Lu, K. Ueda, H. Yagi, and T. Yanagitani,” Diode-end-pumped 4.2 W Continuous Wave Yb: $\mathrm{Y}_{2} \mathrm{O}_{3}$ Ceramic Laser," Opt. Lett, vol. 29, pp. 1212-1214, 2004.

11. B. M. Walsh, J. McMahon, W. C. Edwards, N. Barnes, R. W. Equall, R. L. Hutcheson, J. Opt. Soc. Amer. B, vol. 19, pp. 2893-2903, 2002.

12. Harris, Daniel C., "Materials for Infrared Windows and Domes," SPIE Optical Engineering Press, Bellingham, Washington, 1999.

13. W.B. Grant, Lidar for Atmospheric and Hydrospheric Studies in Tunable Laser Applications, ed. F.J. Duarte, New York: Marcel Dekker, Inc., pp. 241, 1995.

14. H. Gleiter, "Nanocrystalline Materials", Progress in Materials Science, vol. 33, issue 4, 1989 pp. 223-315.

15. R. W. Siegel, "Synthesis and Properties of Nanophase Materials", Mat. Sci. Eng. A: Structural Materials: Properties, Microstructure and Processing, vol. 2, pp. 189-197,1993.

16. B.H. Kear, V. Shukla and R. K. Sadangi, "Metastable nanostructured materials and method for production of the same", Provisional patent application, October 2004.

17. R.K. Sadangi, V. Shukla and B.H. Kear, "Processing and Properties of $\mathrm{ZrO}_{2}\left(3 \mathrm{Y}_{2} \mathrm{O}_{3}\right)-\mathrm{Al}_{2} \mathrm{O}_{3}$ Nanocomposites," Journal of Refractory metals and hard materials, Vol.23 pp 363-368 2005.

18. S.B. Trivedi, S.W. Kutcher, C.C. Wang, G.V. Jagannathan, K. jia, R. Rosemeier. "Solid-state ceramic laser material for remote sensing of ozone using Nd:Yttria" On-going Phase II 
Contract \#NNL06AA21C. Dec 2005 - Dec 2007. Sponsored by NASA Langley Research Center.

19. Narasimha S. Prasad, Sudhir B. Trivedi, Susan Kutcher, Chen-Chia Wang, G. Jagannathan, Uwe Hommerich, Vijay Shukla, Rajendra Sandangi, Bernard Kear. "Development of solidstate ceramic material using Nd:Yttria", Solid State Lasers XV: Technology and Devices. Proc. of SPIE, vol. 6100, pp. 287-296, 2006.

20. Narasimha S. Prasad, S. B. Trivedi, S. Kutcher, C.C. Wang, G. Jagannathan, U. Hommerich, V. Shukla, R. Sandangi, "Development of solid-state laser material using ceramic Yttria," Proc. of SPIE, vol. 5887, pp. 17-1 to 17-6, 2005. 